\title{
Intensive insulin therapy protects the endothelium of critically ill patients
}

\author{
Lies Langouche, ${ }^{1}$ Ilse Vanhorebeek, ${ }^{1}$ Dirk Vlasselaers, ${ }^{1}$ Sarah Vander Perre,, ${ }^{1}$ Pieter J. Wouters, ${ }^{1}$ \\ Kristin Skogstrand, ${ }^{2}$ Troels K. Hansen, ${ }^{3}$ and Greet Van den Berghe ${ }^{1}$
}

${ }^{1}$ Department of Intensive Care Medicine, Katholieke Universiteit Leuven, Leuven, Belgium. 2Department of Clinical Biochemistry, Statens Serum Institut, Copenhagen, Denmark. ${ }^{3}$ mmmunoendocrine Research Unit, Medical Department M, Aarhus University Hospital, Aarhus, Denmark.

\begin{abstract}
The vascular endothelium controls vasomotor tone and microvascular flow and regulates trafficking of nutrients and biologically active molecules. When endothelial activation is excessive, compromised microcirculation and subsequent cellular hypoxia contribute to the risk of organ failure. We hypothesized that strict blood glucose control with insulin during critical illness protects the endothelium, mediating prevention of organ failure and death. In this preplanned subanalysis of a large, randomized controlled study, intensive insulin therapy lowered circulating levels of ICAM-1 and tended to reduce E-selectin levels in patients with prolonged critical illness, which reflects reduced endothelial activation. This effect was not brought about by altered levels of endothelial stimuli, such as cytokines or VEGF, or by upregulation of eNOS. In contrast, prevention of hyperglycemia by intensive insulin therapy suppressed iNOS gene expression in postmortem liver and skeletal muscle, possibly in part via reduced NF- $\mathrm{KB}$ activation, and lowered the elevated circulating NO levels in both survivors and nonsurvivors. These effects on the endothelium statistically explained a significant part of the improved patient outcome with intensive insulin therapy. In conclusion, maintaining normoglycemia with intensive insulin therapy during critical illness protects the endothelium, likely in part via inhibition of excessive iNOS-induced NO release, and thereby contributes to prevention of organ failure and death.
\end{abstract}

\section{Introduction}

Critically ill patients requiring intensive care for more than a few days have a high risk of death (1). Most intensive care deaths beyond the first few days of critical illness are attributable to nonresolving organ failure, either due to or coinciding with sepsis. An increased susceptibility to infections and the sequelae of an excessive systemic inflammatory response to infection and injury play a role.

The vascular endothelium controls vasomotor tone and microvascular flow and regulates trafficking of nutrients and several biologically active molecules $(2,3)$. Local activation of the endothelium is crucial for infection control, but widespread systemic endothelial activation may lead to deleterious consequences $(3,4)$. In the process of endothelial cell activation, expression of adhesion molecules such as E- and P-selectin, ICAMs, and VCAMs on the cell surface is induced. These adhesion molecules activate leukocytes and increase rolling and strong adherence of leukocytes to the endothelium with subsequent migration into the underlying tissue (3). Endothelial production and shedding of adhesion molecules is stimulated by proinflammatory cytokines and growth factors, such as VEGF, expressed and released by injured tissues. Release of reactive oxygen species and several proteases by activated leukocytes further contributes to endothelial cell and tissue damage. Other consequences of endothelial activation and damage include increased microvascular permeability with capillary leakage and coagulopathy $(2,4)$. Obstruction of the microcirculatory blood vessels, resulting from excessive leukocyte adhesion and

Nonstandard abbreviations used: CI, confidence interval; CRP, C-reactive protein; $\mathrm{ICU}$, intensive care unit; IQR, interquartile range; nNOS, neuronal NOS; OR, odds ratio. Conflict of interest: G. Van den Berghe holds an unrestrictive Katholieke Universiteit Leuven Novo Nordisk Chair of Research.

Citation for this article: J. Clin. Invest. 115:2277-2286 (2005). doi:10.1172/JCI25385. aggregation together with intravascular coagulation and thrombosis, hampers perfusion, thus bringing about cellular hypoxia, which may lead to organ failure and death $(2,3)$.

$\mathrm{NO}$ is pivotal in this process via its vasodilatory properties and through its control of the interaction between the endothelium and leukocytes. NO results from L-arginine oxidation by a family of enzymes called NOS. There are 2 constitutive NOS isoforms, neuronal NOS (nNOS) and eNOS. nNOS was first described in brain, but other tissues, such as spinal cord and skeletal muscle, also express nNOS (5). Likewise, although eNOS is predominantly expressed in the endothelium, it is also detectable in other cell types, including hepatocytes and muscle cells (reviewed in refs. 6, 7). iNOS is an isoform that can be induced by several stimuli in virtually every cell type (reviewed in ref. 8). Low concentrations of $\mathrm{NO}$, generated in basal circumstances by the constitutive enzyme eNOS, have been shown to exert antiadhesive and protective properties, whereas high NO concentrations, generated predominantly by iNOS, are proinflammatory and may evoke organ damage in conditions of ischemia and reperfusion (9) (Figure 1).

In a recent large, randomized controlled study of surgical intensive care patients, we showed that the use of intensive insulin therapy to maintain strict normoglycemia reduced the risk of organ failure and death (10). The intervention beneficially affected innate immunity (11), exerted an antiinflammatory effect (12), improved the deranged lipid profile (13), and protected hepatocytic mitochondrial ultrastructure and function (14). We here hypothesize that strict blood glucose control with insulin during critical illness also protects the endothelium, which in turn is likely to play a role in the observed prevention of organ failure and reduced mortality. Since eNOS gene transcription and activity are known to be upregulated by insulin (6), and iNOS activation may be downregulated by insulin and through the prevention of hyperglycemia, we hypothesized that such effects of insulin would mediate endothe- 


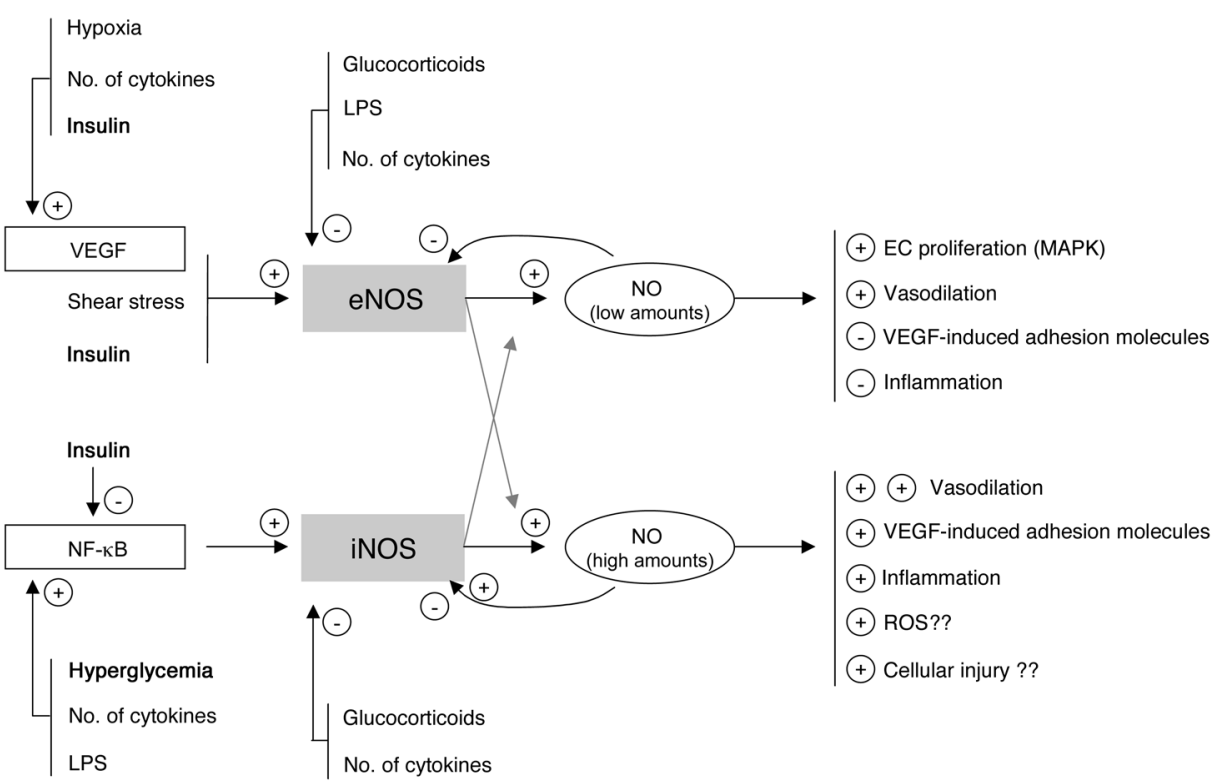

\section{Figure 1}

Simplified concept and rationale of the study. Low concentrations of NO, normally generated by eNOS, are likely to be beneficial for the endothelium and organ function, whereas high concentrations of NO, generated via iNOS induction, may contribute to endothelium dysfunction, excessive vasodilation, extravasation, and tissue injury. Insulin-titrated prevention of hyperglycemia during critical illness may theoretically protect the endothelium via its effects on eNOS and iNOS expression and activity. lial protection (Figure 1). We tested this hypothesis by studying the effect of intensive insulin therapy on circulating levels of the adhesion molecules ICAM-1 and E-selectin and endothelial stimuli such as VEGF and cytokines; by quantifying tissue gene expression and protein levels of different members of the NOS family and involvement of NF- $\mathrm{KB}$ activation as a possible regulatory mechanism; and by measuring circulating NO levels.

\section{Results}

Blood glucose control and clinical outcome. Table 1 shows the baseline characteristics of all patients with prolonged critical illness (intensive care unit [ICU] stay of at least 1 week) and Table 2 those of all nonsurvivors from whom biopsies were available, randomized for conventional or intensive insulin therapy (see Methods for a description of patients and randomization).

Blood glucose levels upon admission were comparable in both treatment groups. According to the study protocol, mean morning blood glucose levels were significantly lower in the group receiving intensive insulin therapy (normoglycemia) than in the group undergoing conventional treatment (Figure 2). In the former group, higher insulin doses were needed to achieve the targeted glucose levels (Figure 2). Glucose control was maintained until the last study day. As in the whole study population (10), in this group of patients with prolonged critical illness, intensive insulin therapy significantly reduced mortality, the incidence of bacteremia, the risk of acute renal failure requiring
Table 1

Baseline characteristics of patients with prolonged critical illness (ICU stay $\geq 1$ week)

dialysis or continuous veno-venous hemofiltration, the need for mechanical ventilation, and the length of stay in the ICU (Table 3). The need for glucocorticoid administration was similar in the 2 treatment groups. Of the patients with prolonged critical illness, $32 \%$ in the conventional and $36 \%$ in the intensive insulin therapy group received glucocorticoids at some time during intensive care $(P=0.3)$. Glucocorticoids were more often needed in nonsurvivors than survivors, a reflection of the severity of disease, but among the nonsurvivors, similar fractions of the conventional (53\%) and intensive (56\%) groups received glucocorticoid therapy $(P=0.8)$. All the effects of intensive insulin therapy described below were unaffected by glucocorticoid treatment or by the presence of bacteremia (data not shown).

Conventional insulin
therapy $(\boldsymbol{n}=\mathbf{2 2 4})$
$150(67)$
$61 \pm 16$
$25.7 \pm 5.6$
$21(9)$
$50(22)$

Positive history of malignancy (no. [\%])

Reason for admission or type of surgery (no.)

Complicated vascular

Complicated abdominal

Complicated cardiothoracic

Multiple trauma and cerebral injury

Solid organ transplant/hemato/other

APACHE II score (first 24 hours; median [IQR])

TISS-28 score (first 24 hours; median [IQR])

Blood glucose upon admission (mg/dl; mean \pm SD)

Hyperglycemia ( $\geq 200 \mathrm{mg} / \mathrm{dl}$ ) upon admission (no. [\%])

$\begin{array}{cc}\begin{array}{c}\text { Intensive insulin } \\ \text { therapy }(\boldsymbol{n}=\mathbf{1 8 1})\end{array} & \boldsymbol{P} \\ 125(69) & 0.7 \\ 61 \pm 15 & 0.9 \\ 25.8 \pm 4.7 & 0.8 \\ 18(10) & 0.8 \\ 42(23) & 0.8 \\ & 0.7\end{array}$

$\begin{array}{ccc}14 & 18 & \\ 31 & 26 & \\ 103 & 75 & \\ 52 & 42 & \\ 24 & 20 & 0.7 \\ 12(8-15) & 11(8-16) & 0.5 \\ 39(33-45) & 39(35-45) & 0.6 \\ 148 \pm 56 & 145 \pm 52 & 0.7 \\ 33(15) & 24(13) & \end{array}$

The APACHE II, or Acute Physiology and Chronic Health Evaluation II, score denotes the severity of illness, with severely ill patients having higher scores (15). TISS-28 is a simplified Therapeutic Intervention Scoring System, with higher values reflecting more invasive treatments (68). Hemato, hematological cancer or bone marrow transplantation; other, other cause. 
Table 2

Baseline characteristics of patients who died in the ICU

\begin{tabular}{lccr}
\hline & $\begin{array}{c}\text { Conventional insulin } \\
\text { therapy }(\boldsymbol{n = 4 9 )}\end{array}$ & $\begin{array}{c}\text { Intensive insulin } \\
\text { therapy }(\boldsymbol{n}=\mathbf{2 7})\end{array}$ & $\boldsymbol{P}$ \\
Sex (no. [\% male]) & $32(65)$ & $20(74)$ & 0.4 \\
Age (yr; mean \pm SD) & $69 \pm 12$ & $69 \pm 13$ & $>0.9$ \\
BMI (mean \pm SD) & $24.7 \pm 3.2$ & $26.3 \pm 5.9$ & 0.1 \\
Positive history of diabetes (no. [\%]) & $4(8)$ & $1(4)$ & 0.5 \\
Positive history of malignancy (no. [\%]) & $15(31)$ & $9(33)$ & 0.8 \\
Reason for admission or type of surgery (no.) & & & 0.4 \\
$\quad$ Complicated vascular & 1 & 2 & \\
$\quad$ Complicated abdominal & 7 & 5 & \\
$\quad$ Complicated cardiothoracic & 28 & 7 & \\
$\quad$ Multiple trauma and cerebral injury & 8 & 1 & \\
$\quad$ Solid organ transplant-hemato-other & 5 & $16(10-18)$ & 0.5 \\
APACHE Il score (first 24 hours; median [IQR]) & $12(10-19)$ & $159 \pm 67$ & 0.5 \\
TISS-28 score (first 24 hours; median [IQR]) & $41(34-48)$ & $6(22)$ & 0.4 \\
Blood glucose upon admission (mg/dl; mean \pm SD) & $157 \pm 75$ & & \\
Hyperglycemia ( $\geq 200$ mg/dl) upon admission (no. [\%]) & $7(14)$ & & \\
\hline
\end{tabular}

Endothelial stimuli. Serum VEGF levels upon ICU admission were comparable between patients in the conventional and intensive insulin treatment groups [median, 427 $\mathrm{pg} / \mathrm{ml}$ (interquartile range [IQR], 213-640 $\mathrm{pg} / \mathrm{ml}$ ) versus $320 \mathrm{pg} / \mathrm{ml}$ (IQR, 152-552 pg/ml), respectively; $P=0.2]$. Day 7 serum VEGF levels were a median 2 -fold higher than the admission levels, irrespective of the insulin treatment $(835 \mathrm{pg} / \mathrm{ml}$ [IQR, 471-1,336 pg/ml] in the conventional group and $786 \mathrm{pg} / \mathrm{ml}$ [468-1,216 pg/ml] in the intensive insulin group; $P=0.5$ ]. VEGF levels were lower in nonsurvivors than in survivors $(P=0.04)$. Lower VEGF levels were also associated with the risk for developing acute renal failure (data not shown).

Upon admission to ICU, patients

The levels of the inflammatory marker C-reactive protein (CRP) were systematically evaluated during ICU stay (Figure 2). Compared with conventional therapy, intensive insulin therapy lowered serum CRP levels at all time points. The levels of CRP on day 7 were higher in nonsurvivors than in survivors.

Shedded adhesion molecules: serum ICAM-1 and E-selectin levels. Serum ICAM-1 and E-selectin levels upon ICU admission were comparable between patients in the conventional and intensive insulin treatment groups (Figure 3). Serum ICAM-1 levels were strongly increased on day 7 in both treatment groups, but this rise was a median $14 \%$ lower in the patients who received intensive insulin therapy compared with conventional insulin therapy (Figure 3; $P=0.009$ ). In contrast to ICAM-1 levels, day 7 levels of E-selectin were not higher than the levels at admission (Figure 3). Nevertheless, E-selectin levels at day 7 tended to be lower $(13 \%$ median reduction; $P=0.08$ ) in intensive insulin-treated patients compared with those receiving conventional therapy.

Univariate analysis revealed that ICAM-1 and E-selectin levels were higher in nonsurvivors than in survivors $(P<0.0001$ and $P=0.01$, respectively). Elevated levels of ICAM-I and E-selectin were also associated with the risk for developing acute renal failure (data not shown). A weak, albeit highly significant, correlation was observed between CRP and ICAM-1 levels $(r=0.326 ; P<0.0001)$ and between CRP and E-selectin levels $(r=0.277 ; P<0.0001)$. in the conventional and intensive insulin therapy groups had equal serum levels of all studied cytokines (data not shown). As compared with conventional therapy, intensive insulin therapy only significantly lowered serum IL-10 concentrations on day 5 (45 pg/ml [IQR, 21-105 pg/ml] in the conventional group and $32 \mathrm{pg} / \mathrm{ml}$ [IQR, $13-73 \mathrm{pg} / \mathrm{ml}$ ] in the intensive insulin group; $P=0.01)$ and day $15(60 \mathrm{pg} / \mathrm{ml}[\mathrm{IQR}, 21-101 \mathrm{pg} / \mathrm{ml}]$ in the conventional group and $32 \mathrm{pg} / \mathrm{ml}[13-72 \mathrm{pg} / \mathrm{ml}]$ in the intensive insulin group; $P=0.007$ ) and tended to lower serum IL-6 levels only on the last day of intensive care $(62 \mathrm{pg} / \mathrm{ml}$ [IQR, 23-173 $\mathrm{pg} / \mathrm{ml}]$ in the conventional group and $43 \mathrm{pg} / \mathrm{ml}[16-124 \mathrm{pg} / \mathrm{ml}]$ in the intensive insulin group; $P=0.07$ ).

The cytokine profiles over time for all 405 patients together are shown in Table 4. Levels of several cytokines significantly increased with time in intensive care, whereas levels of others decreased. Univariate analysis revealed higher day 5 levels of IL-5 $(P=0.04)$ and IL-8 $(P=0.0003)$ in nonsurvivors than in survivors. Both very low and very high levels of IL- 6 and IL-10 were associated with an increased risk of death (Figure 4).

Serum IL-6 levels correlated positively with CRP levels on admission day $(r=0.165 ; P=0.004)$, day $5(r=0.323 ; P<0.0001)$, day $15(r=0.330 ; P<0.0001)$, and on the last day of intensive care $(r=0.315 ; P<0.0001)$. No clinically relevant correlation was found between levels of serum ICAM-1, E-selectin, and any of the studied cytokines (data not shown).
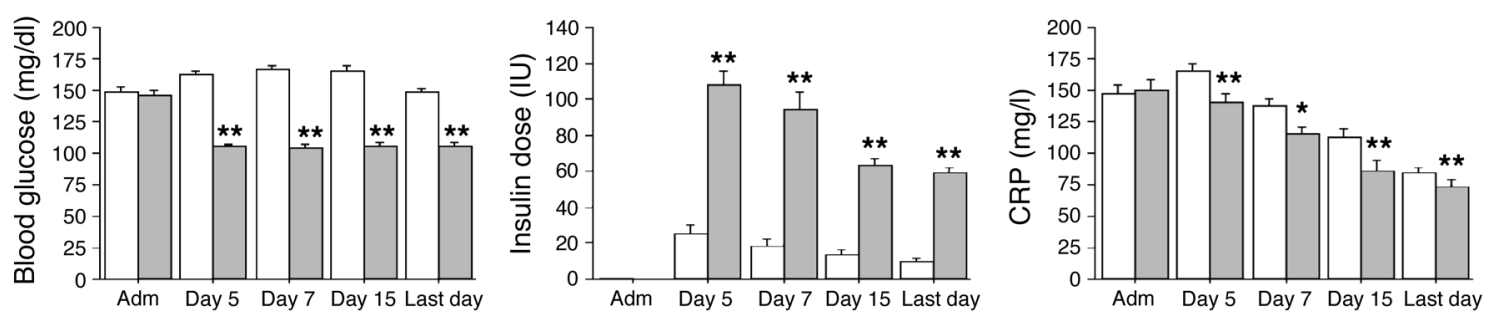

Figure 2

Blood glucose control, insulin doses, and CRP serum levels. White bars represent patients who received conventional insulin therapy ( $n=224)$, gray bars patients who received intensive insulin therapy $(n=181)$. Data are expressed as mean \pm SEM. Adm, admission day. ${ }^{\star} P \leq 0.05$; ${ }^{* *} P \leq 0.01$. 
Table 3

Clinical outcome of patients with prolonged critical illness (ICU stay $\geq 1$ week)

\begin{tabular}{lccc}
\hline & $\begin{array}{c}\text { Conventional insulin } \\
\text { therapy }(\boldsymbol{n}=\mathbf{2 2 4})\end{array}$ & $\begin{array}{c}\text { Intensive insulin } \\
\text { therapy }(\boldsymbol{n = 1 8 1})\end{array}$ & $\boldsymbol{P}$ \\
Death in ICU (no. [\%]) & $47(21)$ & $21(12)$ & 0.01 \\
Cause of death (no.) & & & 0.7 \\
$\quad$ Acute hemodynamic collapse & 6 & 3 & \\
$\quad$ MOF with a proven septic focus & 23 & 7 & \\
$\quad$ MOF with SIRS & 16 & 10 & \\
$\quad$ Severe brain damage & $59(26)$ & $31(17)$ & 0.03 \\
Bacteremia (no. [\%]) & $58(26)$ & $30(17)$ & 0.02 \\
Acute renal failure requiring CVVH (no. [\%]) & $13(8-24)$ & $11(7-18)$ & 0.03 \\
Days on mechanical ventilation (median [IQR]) & $15(11-28)$ & $14(9-24)$ & 0.02 \\
Days in ICU (median [IQR]) & & & \\
\hline
\end{tabular}

MOF, multiple organ failure; SIRS, systemic inflammatory response syndrome; $\mathrm{CVVH}$, continuous veno-venous hemofiltration for renal replacement therapy. renal failure $(P<0.0001$; data not shown). A highly significant but weak correlation was found between day $7 \mathrm{NO}$ quartiles and ICAM-1 $(\rho=0.248 ; P<0.0001)$; NO and E-selectin $(\rho=0.192 ; P=0.0001)$; and $\mathrm{NO}$ and CRP $(\rho=0.192 ; P=0.0001)$.

Relative impact of the studied effects of intensive insulin therapy on improved survival from critical illness. To weigh the impact of intensive insulin therapy on the levels of CRP, VEGF, adhesion molecules, cytokines, and $\mathrm{NO}$ on the outcome benefit of the intervention against blood glucose control, insulin dose, and preexisting risk factors, we performed multivariate logistic regression analysis with ICU mortality as endpoint. Before NO was entered into the model, the lowering of serum ICAM-1 (odds ratio [OR], 1.104 per $100 \mathrm{ng} / \mathrm{l}$ added; 95\% confidence interval

Tissue gene and protein expression of the NOS family. Hepatic $(P=0.4)$ and skeletal muscle $(P=0.1)$ eNOS mRNA levels were not significantly altered by insulin treatment (Figure 5). In liver, nNOS mRNA was undetectable; in skeletal muscle, nNOS gene expression was unaffected by intensive insulin therapy (median, 0.81 [IQR, 0.321.42 ] in the intensive insulin group versus 0.40 [IQR, $0.15-1.10$ ] in the conventional group; $P=0.2$ ). In contrast, iNOS gene expression was a median $66 \%$ lower in liver $(P=0.01)$ and a median $21 \%$ lower in skeletal muscle $(P=0.04)$ of intensive insulin treated patients as compared with conventionally treated patients (Figure 5).

Intensive insulin therapy did not affect eNOS protein levels in liver $(865 \mathrm{pg} / \mathrm{mg}$ [IQR, 778-1,096 pg/mg] protein in the intensive insulin group versus $935 \mathrm{pg} / \mathrm{mg}$ [IQR, 786-1,060 pg/mg] protein in the conventional group; $P=0.6)$ or skeletal muscle $(144 \mathrm{pg} / \mathrm{mg}$ [IQR, 93-180 $\mathrm{pg} / \mathrm{mg}$ ] protein in the intensive insulin group versus $127 \mathrm{pg} / \mathrm{ml}$ [IQR, 94-181 pg/mg] protein in the conventional group; $P=0.7)$. Unfortunately, attempts to quantify iNOS protein levels with either of 2 commercially available antibodies or by ELISA were not successful, due to lack of specificity.

There was no correlation between any of the measured cytokines and iNOS, eNOS, or nNOS gene expression. Also, CRP levels measured on the last day of intensive care did not correlate with NOS gene expression.

Intensive insulin therapy did not affect phosphorylated IкB levels in skeletal muscle but tended to lower phosphorylated ІкB levels in liver $(P=0.1)$, which reflects a trend toward lower NF-кB activation (Figure 5).

Serum NO levels. Compared with those in control subjects, NO levels upon ICU admission were significantly increased in critically ill patients $(P=0.002)$, to a similar extent for the conventional and intensive insulin treatment groups (Figure 6). In the conventional treatment group, NO levels remained equally high on day $7(P=0.5$; Figure 6$)$. In contrast, a significant decrease was seen for the patients in the intensive insulin therapy group between admission and day $7(P=0.02)$, which resulted in significantly lower levels in these patients versus conventionally treated patients $(P=0.04)$. This difference was due to a downward shift in the levels of the 2 upper quartiles (Figure 6).

Univariate analysis revealed that NO serum levels were higher in nonsurvivors than in survivors $(P<0.0001)$. Elevated NO serum levels were also associated with the risk for developing acute
[CI], 1.017-1.199; $P=0.02)$ and E-selectin (OR, 1.050 per $5 \mathrm{ng} / \mathrm{l}$ added; 95\% CI, 1.008-1.093; $P=0.02$ ) levels explained at least part of the reduced mortality with intensive insulin therapy, independent of and corrected for severity of illness (APACHE II score; ref. 15, age, and the level of blood glucose control. Addition of $\mathrm{NO}$ to the model rendered the predictive effect of ICAM-1 (OR, 1.083 per $100 \mathrm{ng} / \mathrm{l}$ added; 95\% CI, 0.996-1.178; $P=0.06)$ and E-selectin (OR, 1.041 per $5 \mathrm{ng} / \mathrm{l}$ added; 95\% CI, 0.999-1.085; $P=0.05$ ) levels only borderline significant. Levels of $\mathrm{NO}$ in the 2 upper quartiles accounted for this association with adverse outcome (50-75\% quartile: OR, 6.335, 95\% CI, $1.551-25.870, P=0.01$; 75-100\% quartile: OR, $8.474,95 \% \mathrm{CI}$, 2.001-35.891, $P=0.004)$. Similar results were obtained with multivariate logistic regression analysis for developing acute renal failure as outcome parameter (data not shown).

\section{Discussion}

As compared with conventional therapy, intensive insulin therapy lowered circulating levels of ICAM-1 and E-selectin in patients with prolonged critical illness, which reflected reduced activation of the endothelium. Reduced endothelial activation with insulin
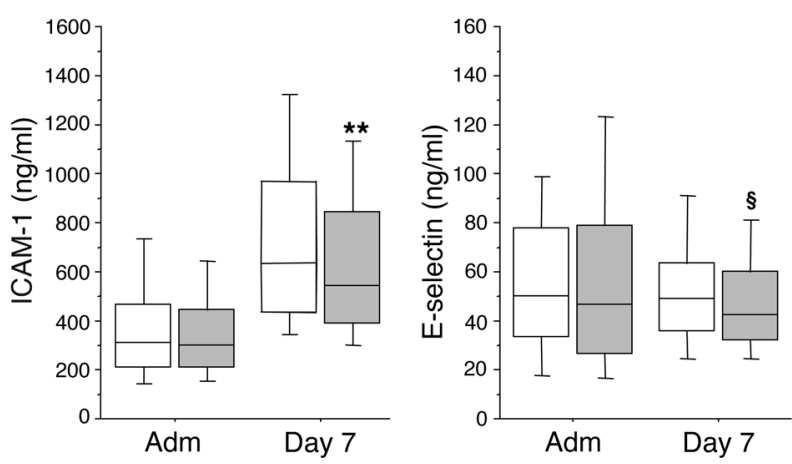

\section{Figure 3}

Serum ICAM-1 and E-selectin levels. Data are presented as box plots; the central line indicates the median, the box the IQR, and the whiskers the 10 th and 90 th percentiles. White boxes represent the patients in the conventional insulin therapy group $(n=222)$, gray boxes patients in the intensive insulin therapy group $(n=181)$. For 2 patients, serum samples were not available. ${ }^{\star \star} P \leq 0.01 ;{ }^{\S} P \leq 0.1$. 


\section{Table 4}

Serial measurements of cytokines in serum

\begin{tabular}{|c|c|c|c|c|c|}
\hline & $\begin{array}{c}\text { Admission day } \\
(n=395 ; \text { median }[\text { IQR]) }\end{array}$ & $\begin{array}{c}\text { Day } 5 \\
(n=404 ; \text { median }[\text { IQR }])\end{array}$ & $\begin{array}{c}\text { Day } 15 \\
(n=207 ; \text { median }[\text { IQR }])\end{array}$ & $\begin{array}{c}\text { Last day } \\
(n=404 ; \text { median [IQR]) }\end{array}$ & $P$ \\
\hline $\mathrm{IL}-1 \beta(\mathrm{pg} / \mathrm{ml})$ & $9.0(3.4-17.6)$ & $10.1(4.2-18.6)$ & $13.2(6.5-30.8)$ & $13.1(6.2-26.1)$ & $<0.0001$ \\
\hline IL-2 (pg/ml) & $4.0(1.1-13.0)$ & $4.3(1.2-14.9)$ & $5.5(1.7-21.1)$ & $6.6(1.8-20.8)$ & $<0.0001$ \\
\hline IL-4 (pg/ml) & $6.6(3.0-10.7)$ & $6.5(3.2-10.7)$ & $6.9(3.2-12.2)$ & $7.1(3.4-11.5)$ & 0.2 \\
\hline $\mathrm{IL}-5(\mathrm{pg} / \mathrm{ml})$ & $6.4(3.1-14.1)$ & $7.9(3.6-15.3)$ & $8.4(4.0-17.8)$ & $6.8(2.8-14.8)$ & 0.08 \\
\hline IL-6 (pg/ml) & $193.5(49.6-500.0)$ & 77.3 (27.0-206.9) & $73.1(30.2-237.2)$ & $51.6(17.7-155.6)$ & $<0.0001$ \\
\hline IL-8 (pg/ml) & $70.6(28.7-208.2)$ & $61.6(22.2-155.0)$ & $85.4(36.1-226.2)$ & $74.0(25.3-160.2)$ & 0.1 \\
\hline $\mathrm{IL}-10(\mathrm{pg} / \mathrm{ml})$ & $61.6(29.8-137.1)$ & $39.4(16.4-89.6)$ & $44.2(15.7-82.8)$ & $39.9(13.8-87.7)$ & $<0.0001$ \\
\hline IL-12 (pg/ml) & $25.8(6.2-92.8)$ & $23.1(7.2-101.7)$ & $47.4(15.3-303.8)$ & $49.7(11.1-217.0)$ & $<0.0001$ \\
\hline TNF- $\alpha(p g / m l)$ & $7.5(2.4-21.3)$ & $7.2(2.5-22.3)$ & $10.5(4.3-36.2)$ & $10.1(3.8-29.2)$ & 0.0005 \\
\hline TNF- $\beta$ (ng/ml) & $0.59(0.21-2.09)$ & $0.51(0.17-1.88)$ & $0.96(0.41-3.30)$ & $1.14(0.41-4.49)$ & $<0.0001$ \\
\hline RANTES (ng/ml) & $20.9(7.6-55.5)$ & $22.2(7.3-59.0)$ & $48.4(15.0-91.1)$ & $36.9(13.3-81.1)$ & $<0.0001$ \\
\hline $\mathrm{BDNF}(\mathrm{ng} / \mathrm{ml})$ & $5.1(3.1-8.0)$ & $4.8(3.0-7.7)$ & $7.0(4.1-10.6)$ & $6.8(4.0-10.8)$ & $<0.0001$ \\
\hline MCP1 (pg/ml) & $12.1(2.8-110.1)$ & $5.2(2.0-28.7)$ & $9.5(2.6-56.2)$ & $6.7(2.0-42.8)$ & 0.0002 \\
\hline IFN- $\gamma(p g / m l)$ & $9.8(2.7-24.5)$ & $8.4(2.8-22.3)$ & $11.3(5.1-44.0)$ & $13.1(4.4-34.7)$ & 0.02 \\
\hline
\end{tabular}

therapy was not brought about by an effect on endothelial stimuli, such as VEGF or cytokines, nor by upregulation of eNOS, an unexpected observation. In contrast, prevention of hyperglycemia by intensive insulin therapy suppressed iNOS gene expression and lowered circulating NO levels. These effects on the endothelium statistically explained a significant part of the improved patient outcome with intensive insulin therapy.

Intensive insulin therapy reduced the circulating levels of the adhesion molecules ICAM-1 and E-selectin in critically ill patients, independent of its effect on infection prevention. E-selectin is produced selectively by endothelial cells and is rapidly inducible and, as such, reflects the state of the endothelium in disease. ICAM-1 is constitutively expressed at very low levels on the endothelium and is highly inducible upon cell activation. It is also expressed by fibroblasts and hematopoietic cells. Small changes in the expression of the adhesion molecules at the endothelial cell level may go undetected in the circulation, but when differences in the amount of shedded adhesion molecules are found, this indicates a substantial change in activity status of the endothelium. The lowering of ICAM-1 and E-selectin levels with intensive insulin therapy partially explained the reduced risk of developing organ failure and of death with this intervention, as indicated by logistic regression analysis. The data thus suggest that endothelial protection with insulin therapy played a role in bringing about the prevention of organ damage and improved survival. Several studies have previously underscored the importance of adhesion molecules and leukocyte-endothelium interactions in determining patient outcome. First, higher levels of circulating E-selectin and ICAM-1 are found in critically ill patients as compared with healthy individuals (4, 16-20). Furthermore, E-selectin and ICAM-1 levels further rise or remain persistently elevated in patients with multiple organ dysfunction and in nonsurvivors as compared with survivors (16, $17,19,21)$. Especially ICAM-1 appeared to independently predict subsequent development of multiple organ failure and/or death $(17,19,20)$. Second, E-selectin levels have been found to correlate with hemodynamic instability $(18,22)$. Also, a correlation between release of adhesion molecules into the circulation and severity of trauma has been reported (4). Third, animal studies on interven- tions with monoclonal antibodies to adhesion molecules demonstrated that inhibition of neutrophil adherence to endothelial cells significantly protects against reperfusion injury (23), acute lung injury, and death (24).

A potent trigger of endothelial cell activation and expression of adhesion molecules is VEGF. VEGF levels strongly increased with time in patients with prolonged critical illness. In contrast to the effect of glycemic control in patients with diabetes mellitus (25, 26) and of insulin infusion in fasting, obese, nondiabetic subjects (27), intensive insulin therapy did not attenuate the critical illnessinduced rise in VEGF levels. This apparent discrepancy is likely explained by the fact that critical illness induces more pronounced insulin resistance than do type 2 diabetes and obesity. The rise of VEGF in the critically ill is not surprising, considering it is a key regulator of angiogenesis (28) involved in the repair of tissue injury $(29,30)$. Moreover, VEGF expression is potentiated by hypoxia (29). Strongly enhanced levels of VEGF have been previously reported in critically ill patients with diverging underlying diseases (31-33). Interestingly, administration of VEGF in experimental models of

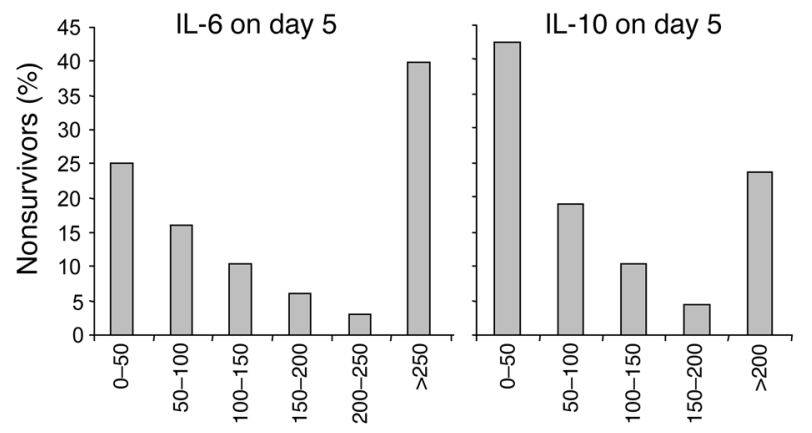

\section{Figure 4}

Relationship between serum levels of IL- 6 and IL-10 and mortality. Day $5 \mathrm{IL}-6$ and IL-10 levels of the whole group of patients $(n=405)$ were stratified and, in each class, the percentage of survivors relative to the number of patients was determined. Indicated ranges are expressed in picograms/milliliter. 

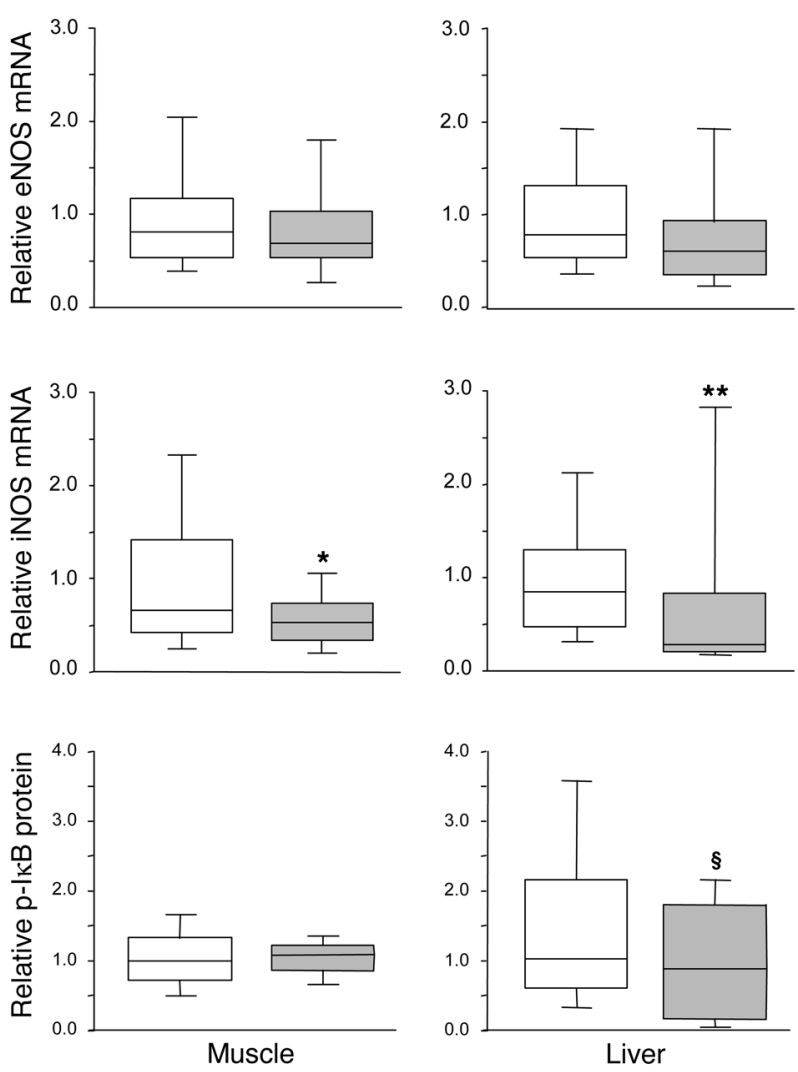

trauma-induced injury beneficially affected outcome $(34,35)$. The higher VEGF levels observed in the survivors versus nonsurvivors in our study also point to an association between low VEGF levels and adverse outcome. Since insulin therapy did not affect circulating VEGF levels, the impact on adhesion molecules was not mediated via an effect on this potent endothelial stimulus.

Also, a number of proinflammatory cytokines trigger endothelial cell activation (Figure 1), which in turn plays a role in the host response to infection. It is thought that both inadequate control of infection and an excessive release of cytokines into the systemic circulation play a role in microvascular injury and multiple organ failure (36). The cytokine profiles we documented in the patients with prolonged critical illness revealed a concomitant pro- and antiinflammatory response with an immediately high and further increasing level of antiinflammatory cytokines (IL-4 and brainderived neurotrophic factor $[\mathrm{BDNF}]$ ) and a massive and progressive further rise in the concentration of proinflammatory cytokines (IL-1 $\beta$, IL- 2 , IL-12, IFN- $\gamma$, TNF- $\alpha$ and TNF- $\beta$, and RANTES). In contrast, initially high circulating levels of the proinflammatory

\section{Figure 6}

Serum NO levels. Data are presented as box plots; the central line indicates the median, the box the IQR, and the whiskers the 10th and 90 th percentiles. Patients were compared with healthy volunteers (dark gray box; $n=30$ ). White boxes represent the patients in the conventional insulin therapy group ( $n=50$ on admission, $n=222$ on day 7 ), light gray boxes patients in the intensive insulin therapy group $(n=50$ on admission, $n=180$ on day 7 ). ${ }^{*} P \leq 0.05$ versus conventional insulin therapy; ${ }^{\dagger} P \leq 0.05$ day 7 versus admission day; $P \leq 0.05$ versus healthy volunteers; ${ }^{\#} P \leq 0.01$ versus healthy volunteers.

\section{Figure 5}

NOS gene expression and NF-кB activation in postmortem biopsies. Transcript levels of eNOS and iNOS were measured in postmortem liver and skeletal muscle biopsies. NF-KB activation was evaluated in these tissues by analysis of the levels of phosphorylated IкB. Data are presented as box plots; the central line indicates the median, the box the IQR, and the whiskers the 10th and 90th percentiles. iNOS gene expression data were normally distributed. White boxes represent the patients in the conventional insulin therapy group $(n=49)$, gray boxes patients in the intensive insulin therapy group $(n=27)$. ${ }^{*} P \leq 0.05$; ${ }^{\star \star} P \leq 0.01 ; \S P \leq 0.1$.

cytokines IL-6 and monocyte chemotactic protein 1 (MCP1) and the main antiinflammatory cytokine IL-10 decreased over time. Serum levels of IL-5 and IL-8 were higher in nonsurvivors than in survivors, whereas both too-low and too-high levels of IL-6 as well as IL-10 were associated with a higher risk of organ failure and death (37-39). This U-shaped relationship is in agreement with the deleterious consequences of both the overwhelming proinflammatory response and the prolonged periods of immune suppression present in critical illness (reviewed in ref. 40). We expected insulin therapy to lower proinflammatory cytokine levels in view of its known antiinflammatory effect $(12,41)$. However, intensive insulin therapy had only a mild effect on circulating cytokine levels, independent of its preventive effect on infection, and levels of both the proinflammatory IL- 6 and the antiinflammatory IL-10 were lowered by intensive insulin therapy. Furthermore, the suppression of adhesion molecules preceded an eventual lowering of IL- 6 and, according to the multivariate logistic regression analysis, it appeared that none of the cytokines independently determined the risk of death. Hence, it is unlikely that an effect of insulin on cytokine release plays a major role in insulin's protective effect on the endothelium and organ function, although an influence on local cytokine production cannot be excluded.

Although eNOS gene transcription and activity are known to be upregulated by insulin $(6,42)$, intensive insulin therapy did not alter eNOS gene expression or eNOS protein level in tissue of critically ill patients. This observation, at first sight unexpected, can be explained by insulin resistance in the critically ill. Insulin stimulates eNOS expression through activation of PI3K (43), and in a rat model of critical illness (44) as well as type 2 diabetes mellitus

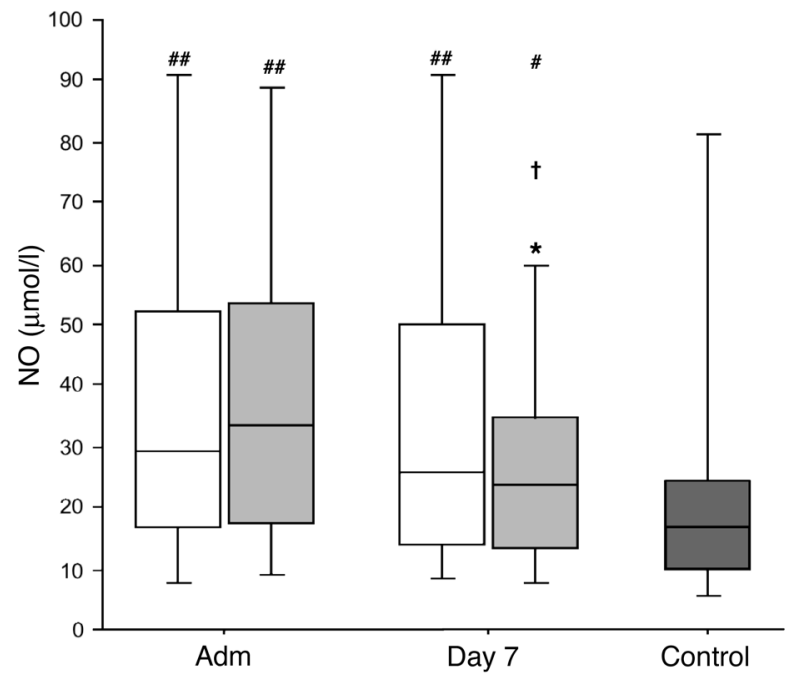


(45), insulin resistance appears to be due to impaired signaling via the insulin receptor substrate/PI3K pathway. Furthermore, Aljada et al. demonstrated that TNF- $\alpha$ inhibits insulin-induced eNOS expression (46). In the present study, the fact that TNF- $\alpha$ levels were high and not affected by insulin therapy might explain the lack of an insulin effect on eNOS expression. However, eNOS gene expression was only measured in the sickest patients, as, for obvious ethical reasons, tissue biopsies were only taken from nonsurvivors. Therefore, an effect on eNOS in survivors cannot be excluded. Finally, since isolation of endothelial cells from the snap-frozen liver and skeletal muscle biopsies was impossible, eNOS expression in hepatocytes and muscle cells may respond differently to insulin therapy than that in endothelial cells, and both cell types were present in the tissue biopsies.

iNOS, as opposed to eNOS, gene expression was lowered by intensive insulin therapy in liver and skeletal muscle of nonsurviving critically ill patients. This was associated with lowered circulating levels of NO in a patient population of both survivors and nonsurvivors, which suggests that the reduced expression of iNOS with insulin therapy coincided with a reduced activity of the enzyme. The exact source of iNOS expression and activity and of the ensuing NO production is not clear from this study, as several cell types present in the studied biopsies, including macrophages (47), may contribute in this process. Since this suppression of NO reflected a blunting of a dramatic increase of circulating levels of $\mathrm{NO}$ in critically ill patients - i.e., intensive insulin therapy reduced the levels in the 2 upper quartiles without affecting the 2 lower quartiles - it likely explains the observed beneficial effects on the endothelium. Indeed, NO explained a significant part of improved survival in multivariate logistic regression analysis independent of ICAM-1 and E-selectin. The observation that the contribution of ICAM-1 and E-selectin remained borderline significant in the model indicates that NO also mediates effects other than modulation of these adhesion molecules. Previous studies have reported elevated serum NO levels in critically ill patients $(39,48)$. High NO levels are proinflammatory and may evoke organ damage in conditions of ischemia and reperfusion, whereas low NO concentrations exert antiadhesive and protective properties (9). Our observation that preventing excessive NO release, via inhibition of excessive iNOS induction without suppression of eNOS, is associated with better outcome of critical illness is in line with previous reports on the effects of NOS inhibitors. Indeed, treatment of septic animals with NOS inhibitors appeared promising and suggested that such inhibitors might be of therapeutic value to improve outcome (49-51). However, although in patients with septic shock, administration of a nonselective NOS inhibitor caused an increase in vascular tone and raised blood pressure (52), it also produced a fall in cardiac output and increased mortality $(52,53)$. Hence, it may be crucial to only prevent the excessive NO release mediated by iNOS and not to negatively influence the protective effects of eNOS, as was shown to occur with intensive insulin therapy in our study.

Proinflammatory cytokines such as IFN- $\gamma$, IL-1 $\beta$, IL- 6 , and TNF- $\alpha$ also induce iNOS expression and lead to cytotoxic overproduction of $\mathrm{NO}$ (reviewed in ref. 8). Since in our study these cytokines were either unaffected by the intervention or their circulating levels were only reduced following the lowering of ICAM-1 and E-selectin levels, it is unlikely that the endothelial protection with insulin therapy could be explained by an effect on cytokines. A direct effect on NF-кB-driven iNOS induction of insulin or of hyperglycemia prevention is more probable (54). When IкB is phosphorylated it loses the capacity to inhibit nuclear translocation of NF-кB (55), and we indeed observed a trend toward lower amounts of phosphorylated IкB in liver of the patients in the intensive insulin therapy group but not in skeletal muscle. The heterogeneity of the cell population in these tissues, in which various cell types besides endothelial cells are present, may explain why statistical significance was not reached. The resistance to metabolic insulin signal transduction in liver biopsies (56) and the stronger effect of intensive insulin therapy on iNOS gene expression in liver compared with muscle of critically ill patients suggest that prevention of hyperglycemia is the likely driving force reducing iNOS activation and $\mathrm{NO}$ production, whereby endothelial protection may ensue. It has indeed been demonstrated that glucose has proinflammatory effects $(57,58)$. However, since glucose uptake in endothelial cells is largely insulin independent, prevention of hyperglycemia may also have protected the endothelium directly via prevention of glucose overload $(14,59)$, part of which may be explained by prevention of oxidative stress (60-64). Nevertheless, our current clinical data cannot entirely rule out more direct actions of insulin on the endothelium, and further studies in our animal model of prolonged critical illness (65) are required to differentiate between the impact of glycemic control and that of nonglycemic effects of insulin.

In summary, maintaining normoglycemia with intensive insulin therapy during critical illness protects the endothelium, directly and/or via inhibition of excessive iNOS induction, and thereby contributes to prevention of organ failure and death in ICU.

\section{Methods}

Patients. For analysis of serum markers, all 405 patients requiring at least 7 days of intensive care in the large $(n=1,548)$ randomized controlled trial on the effects of intensive versus conventional insulin therapy (10) were studied. For this study, blood was taken on the admission day, day 5, day 7 , day 15 , and the last day of intensive care. After centrifugation, serum was kept frozen at $-80^{\circ} \mathrm{C}$ until assay. For the study of gene expression and protein levels of iNOS, eNOS, and nNOS, postmortem biopsy samples of liver (lower right quadrant) and skeletal muscle (right musculus rectus abdominis) were taken from patients in the study who died in the ICU, within minutes after death. Postmortem biopsy samples were available from 76 of 98 ICU nonsurvivors in the study. The tissue samples were snap-frozen in liquid nitrogen and stored at $-80^{\circ} \mathrm{C}$ until analysis.

The detailed study protocol has been described elsewhere (10). In brief, all adult mechanically ventilated patients admitted to the ICU after major surgery were eligible for inclusion in the study. Patients who had been randomly assigned to conventional insulin therapy received insulin only if glucose concentrations exceeded $215 \mathrm{mg} / \mathrm{dl}$, with the aim of keeping concentrations between 180 and $200 \mathrm{mg} / \mathrm{dl}$ (hyperglycemia). Intensive insulin therapy maintained blood glucose levels between 80 and $110 \mathrm{mg} / \mathrm{dl}$ (normoglycemia). The Institutional Review Board of the Katholieke Universiteit Leuven had approved the study protocol. Written informed consent was obtained from the closest family member.

For establishment of a reference range for NO levels, sera from 30 non-critically ill volunteers, matched for $\operatorname{sex}(P=0.9)$, age $(P=0.7)$, height $(P>0.9)$, and weight $(P=0.7)$, were also analyzed.

Circulating levels of ICAM-1, E-selectin, and VEGF. Circulating levels of ICAM-1, E-selectin, and VEGF were determined upon admission in a random sub-selection of 100 patients, 50 in each treatment group, and on day 7 in all 405 patients by a commercially available ELISA according to the manufacturer's instructions (R\&D Systems).

Circulating levels of CRP. Serum CRP levels were measured upon admission and on day 5 , day 15 , and the last day of intensive care by an immunoturbidimetric assay (Roche/Hitachi Modular-P; Roche Diagnostics Corp.). 
Circulating levels of cytokines. On the day of admission and day 5, day 15 , and the last day of intensive care, serum concentrations of cytokines (IL-1 $\beta$, IL-2, IL-4, IL-5, IL-6, IL-8, IL-10, IL-12, TNF- $\alpha$, TNF- $\beta$, RANTES, BDNF, MCP1, and INF- $\gamma$ ) were quantified by a multiplexed microbead suspension ELISA assay using the Luminex 100 system (Luminex Corp.) after optimization and validation of the assay procedure. All incubations were performed at room temperature on a microplate shaker (set at 500 $\mathrm{rpm}$ ). For analysis of serum samples, serum and standard solutions were diluted 1:10 in assay buffer (PBS containing 0.5\% Tween-20 and 1\% BSA). We prepared a filter plate (MultiScreen MABVN 1.2- $\mu \mathrm{m}$ 96-well; Millipore) by pre-wetting it with assay buffer. To each well was subsequently added $50 \mu \mathrm{l}$ extracted sample and a 50- $\mu \mathrm{l}$ suspension of capture $\mathrm{Ab}$-conjugated beads, 1,500 beads per analyte, in assay buffer containing $1 \%$ guinea pig/pig serum (1:1). The capture antibodies were allowed to react with their corresponding antigens during 1 hour of incubation, and unbound material was removed from the beads by filtering the content of the wells through the filter bottom using a MultiScreen Vacuum Manifold (Millipore). The beads were washed twice using $200 \mu \mathrm{l}$ washing buffer (PBS containing $0.5 \%$ Tween) per well. The captured antigens were subsequently reacted for 1 hour with a mixture $(50 \mu \mathrm{l})$ of biotinylated detection antibodies each diluted 1:600 in assay buffer. Fifty microliters of streptavidin-phycoerythrin $20 \mu \mathrm{g} / \mathrm{ml}$ assay buffer (Invitrogen Corp.) was added to the wells, and the incubation continued for an additional 30 minutes. The beads were finally washed twice with $200 \mu \mathrm{l}$ washing buffer and resuspended in $100 \mu \mathrm{l}$ washing buffer. After 15 minutes of shaking, the samples were analyzed on the Luminex 100 according to the manufacturer's instructions.

Expression of $i N O S$, eNOS, and $n N O S$ mRNA in liver and skeletal muscle according to quantitative real-time PCR. Messenger RNA from 76 postmortem liver and skeletal muscle biopsies was isolated and quantified as described previously (56). After quality assessment of the RNA (reported in ref. 56), 66 muscle samples and 59 liver samples were used. Total RNA (liver, $3 \mu \mathrm{g}$; muscle, $1 \mu \mathrm{g}$ ) was reverse-transcribed in a final volume of $20 \mu \mathrm{l}$ under the following conditions: a $12-\mu \mathrm{l}$ mixture containing the RNA, $0.1 \mu \mathrm{l}$ random primers (3 $\mu \mathrm{g} / \mu \mathrm{l}$; Invitrogen Corp.) and $1 \mu \mathrm{l}$ dNTPs (10 mM each; Invitrogen Corp.) was heated to $65^{\circ} \mathrm{C}$ for 5 minutes. Following immediate cooling on ice, an $8-\mu 1$ mixture containing $4 \mu \mathrm{l} \times 5$ first-strand buffer (Invitrogen Corp.), $2 \mu \mathrm{l}$ dithiothreitol (100 nM; Invitrogen Corp.), and $1 \mu \mathrm{l}$ Rase inhibitor (RNaseOUT, $40 \mathrm{U} / \mu \mathrm{l}$; Invitrogen Corp.) in $\mathrm{H}_{2} \mathrm{O}$ and $1 \mu$ l SuperScript II Reverse Transcriptase (200 U/ $\mu$; Invitrogen Corp.) was added. The reverse transcription was carried out by incubating the solution for 15 minutes at $25^{\circ} \mathrm{C}, 50$ minutes at $40^{\circ} \mathrm{C}$, and 15 minutes at $70^{\circ} \mathrm{C}$ before cooling it down to $4^{\circ} \mathrm{C}$. Samples were kept at $-20^{\circ} \mathrm{C}$ until processing by quantitative TaqMan real-time PCR. All liver samples and all muscle samples were reverse transcribed simultaneously. Reactions lacking reverse transcriptase were also run to generate controls for assessment of genomic DNA contamination. All primer pairs were designed to span an intron to exclude genomic DNA amplification: eNOS (GenBank accession number NM_000603): forward primer, 5'-GGCATCACCAGGAAGAAGACC-3' (nt 1,758-1,778), reverse primer, $5^{\prime}$-TCACTCGCTTCGCCATCA-3' (nt 1,831-1,848), TaqMan probe, 5'-CGTGAAGATCTCCGCCTCGCTCAT-3' (nt 1,799-1,822); iNOS (AF068236): forward primer, 5'-TGGATGCAACCCCATTGTC-3' (nt 455473), reverse primer, 5'-TAATGGACCCCAGGCAAGATT-3' (nt 572-592), TaqMan probe, $5^{\prime}$-ACACACTTCACCATAAGGCCAAAGGGATTT-3' (nt 572-556); and nNOS (NM_000620): forward primer 5'-CGAGCCATCGGCTTCAA-3' (nt 2,879-2,895), reverse primer, 5'-GCTTGCGATTTGCCTGTCT-3' (nt 2,985-3,003), TaqMan probe, 5'-CGACCATCCTCTATGC-3' (nt 2,964-2,979). External standards were generated as described previously (56). cDNA was quantified in real time with the ABI PRISM 7700 sequence detector (Applied Biosystems). The 25- $\mu 1$ real-time reaction mixture contained 12.5 $\mu \mathrm{l}$ qPCR MasterMix (Eurogentec), $200 \mathrm{nM}$ forward primer, 200
$\mathrm{nM}$ reverse primer, $200 \mathrm{nM}$ TaqMan probe, $75 \mathrm{ng}$ cDNA for quantification of liver eNOS and iNOS, and $12.5 \mathrm{ng}$ cDNA for quantification of muscle eNOS, iNOS, and nNOS. Gene expression data were corrected for $18 \mathrm{~S}$ ribosomal RNA, quantified using the TaqMan Ribosomal RNA Control Reagents Kit (Applied Biosystems). For 18S amplification, 75 pg liver and $125 \mathrm{pg}$ muscle cDNA were used for each reaction. Unknown samples were run in duplicate together with a series of 10 -fold dilutions (from $10^{8}$ copies to $10^{1}$ copies) of an external standard for generation of a standard curve. The number of cycles required for the standard ranged between 14 and 36 . Samples required on average 28,33 , and 32 cycles for eNOS, iNOS, and nNOS, respectively. Individual samples with a copy number coefficient of variation greater than $20 \%$ were reanalyzed. Every patient sample was analyzed in 2 separate runs. To normalize the data, each datapoint was divided by the mean value obtained for the conventionally treated patient group.

iNOS and eNOS protein levels in liver and skeletal muscle. NOS protein levels were evaluated in postmortem liver and muscle biopsies of 76 patients. Tissue samples were homogenized in a buffer containing $20 \mathrm{mM}$ Tris$\mathrm{HCl}, \mathrm{pH}$ 7.6, $10 \%$ glycerol, $1 \%$ Nonidet P-40, $2 \mu \mathrm{g} / \mathrm{ml}$ aprotinin, $5 \mu \mathrm{g} / \mathrm{ml}$ leupeptin, $0.5 \mu \mathrm{g} / \mathrm{ml}$ pepstatin, $10 \mathrm{mM}$ sodium orthovanadate, $34 \mu \mathrm{g} / \mathrm{ml}$ phenylmethylsulfonyl fluoride, $10 \mathrm{mM}$ sodium pyrophosphate, $100 \mathrm{mM}$ sodium fluoride, and $10 \mathrm{mM}$ EDTA. The homogenates were centrifuged for 5 minutes at $9,500 \mathrm{~g}$ and $4{ }^{\circ} \mathrm{C}$. The protein content in the supernatant was determined with Coomassie Protein Assay Reagent (Pierce Biotechnology Inc.) using a standard curve of BSA. Western blot analysis performed with antibodies raised against eNOS (BD Biosciences - Pharmingen), iNOS (BD Biosciences - Pharmingen and Santa Cruz Biotechnology Inc.), and nNOS (Novus Biologicals Inc.) did not yield reliable results. Therefore, we turned to a commercially available ELISA kit (R\&D Systems) to quantify eNOS protein levels. Sixty micrograms liver or $500 \mu$ g skeletal muscle total protein per $100 \mu \mathrm{l}$ were used in the eNOS assay, which was developed according to the manufacturer's instructions. A similar assay for nNOS was not available. The commercial assay for iNOS, optimized for iNOS detection in cell lines, was not suitable for iNOS quantification in tissue homogenates.

Phosphorylated I $\mathrm{K}$ p protein levels in liver and skeletal muscle. Equal amounts of homogenate proteins $(100 \mu \mathrm{g})$ were separated by denaturing SDS gel electrophoresis in 10\% Bis-Tris polyacrylamide gels (Invitrogen Corp.). After separation, proteins were transferred to nitrocellulose membranes. Membranes were incubated overnight at $4^{\circ} \mathrm{C}$ with the primary $\mathrm{Ab}$ against phosphorylated IкB (Ser32/36; Cell Signaling Technology) and with a rabbit anti-mouse HRP-conjugated secondary Ab (DakoCytomation) for 1 hour before development using enhanced chemiluminescence technology (PerkinElmer). Blots were then analyzed using ImageMaster Software 1D Elite (Amersham Biosciences). To normalize the data, each datapoint was divided by the mean value obtained for the conventionally treated patient group.

Circulating levels of NO. NO levels were quantified by measurement of serum nitrate plus nitrite levels using nitrate reductase and the colorimetric Griess reaction $(66,67)$. A 1:4 dilution in PBS of the serum samples $(200 \mu \mathrm{l})$ was ultrafiltered $\left(6,000 \mathrm{~g}, 45\right.$ minutes, $\left.4^{\circ} \mathrm{C}\right)$ through $10,000-\mathrm{kDa}$ molecular weight filters (Ultrafree-MC Biomax; Millipore). Fifty microliters each of the filtrates was analyzed in duplicate. A standard curve was prepared ranging from $0 \mu \mathrm{M}$ to $50 \mu \mathrm{M}$ and was included in duplicate in each assay. Nitrate in the standards and samples was converted to nitrite by addition of $50 \mu \mathrm{l}$ PBS with $600 \mathrm{U} / 1$ nitrate reductase from Aspergillus (Roche Diagnostics Corp.) and $100 \mu \mathrm{M}$ NADH (Sigma-Aldrich). Complete conversion was achieved with an incubation time of 4 hours at room temperature, as evaluated by comparison of a converted nitrate standard curve with a nitrite standard curve. Nitrite was then measured after addition of $50 \mu \mathrm{l} \mathrm{PBS}, 50 \mu \mathrm{l}$ \% sulfanilamide in $5 \%$ phosphoric acid and $50 \mu \mathrm{l} 0.1 \%$ $N$-(1-naphthyl)ethylenediamine dihydrochloride. The absorbance was read at $540 \mathrm{~nm}$ and corrected for absorbance at $650 \mathrm{~nm}$. 
Statistical analysis. The results obtained for different groups of patients were compared by the $\chi^{2}$ test for comparison of proportions, Student's $t$ test for comparison of normally distributed data (presented as mean $\pm \mathrm{SD}$ ), and the Mann-Whitney $U$ test and Friedman test for data that were not normally distributed (presented as median and IQR, unless otherwise indicated). Paired comparisons of non-normally distributed variables were performed by the Wilcoxon signed rank test. The significance of correlations between parameters was assessed by calculation of the corresponding Pearson $(r)$ or Spearman $(\rho)$ correlation coefficient.

The improvement of patient outcome due to the relative effects of intensive insulin therapy on serum CRP, VEGF, ICAM-1, E-selectin, NO, and cytokine levels was assessed by multivariate logistic regression analysis. The factors entered into the logistic regression model were (a) baseline risk factors such as age, type, and severity of illness (APACHE II score) (15), hyperglycemia upon admission, history of diabetes and malignancy; (b) the level of blood glucose control and the dose of insulin; and (c) those studied variables (CRP, VEGF, adhesion molecules, NO, and cytokine levels) that upon univariate analysis were significantly related to the studied outcome measures. Variables entered into the model were always checked for skewness. When they revealed a linear relation with the studied outcome measure, they were entered as continuous variables; otherwise a nominal term was entered.
Two-tailed $P$ values less than or equal to 0.05 were considered statistically significant. StatView 5.0.1 software (SAS Institute Inc.) for Macintosh was used for these statistical analyses.

\section{Acknowledgments}

We wish to thank I. Milants for excellent technical assistance. This work was supported by the Fund for Scientific Research, Flanders, Belgium (FWO), the European Commission 6th Framework program EU506965 (CLINICIP), the Research Council of the Catholic University of Leuven, and the Belgian Foundation for Research in Congenital Heart Diseases. L. Langouche is a Postdoctoral Fellow for the FWO.

Received for publication April 18, 2005, and accepted in revised form June 7, 2005.

Address correspondence to: Greet Van den Berghe, Department of Intensive Care Medicine, Katholieke Universiteit Leuven, Herestraat 49, B-3000 Leuven, Belgium. Phone: 32-16-34-40-21; Fax: 32-16-34-40-15; E-mail: greta.vandenberghe@med.kuleuven.be.

Lies Langouche and Ilse Vanhorebeek contributed equally to this work.
1. Takala, J., et al. 1999. Increased mortality associated with growth hormone treatment in critically ill adults. N. Engl. J. Med. 341:785-792.

2. Vallet, B. 2003. Bench-to-bedside review: endothelial cell dysfunction in severe sepsis: a role in organ dysfunction? [review] Crit. Care. 7:130-138.

3. Aird, W.C. 2003. The role of the endothelium in severe sepsis and multiple organ dysfunction syndrome. Blood. 101:3765-3777.

4. Reinhart, K., Bayer, O., Brunkhorst, F., and Meisner, M. 2002. Markers of endothelial damage in organ dysfunction and sepsis [review]. Crit. Care Med. 30(Suppl. 5):S302-S312.

5. Lin, C.S., et al. 1998. Analysis of neuronal nitric oxide synthase isoform expression and identification of human nNOS-mu. Biochem. Biophys. Res. Commun. 253:388-394.

6. Li, H., Wallerath, T., and Forstermann, U. 2002. Physiological mechanisms regulating the expression of endothelial-type NO synthase. Nitric Oxide. 7:132-147.

7. McNaughton, L., et al. 2002. Distribution of nitric oxide synthase in normal and cirrhotic human liver. Proc. Natl. Acad. Sci. U. S. A. 99:17161-17166.

8. Aktan, F. 2004. iNOS-mediated nitric oxide production and its regulation. Life Sci. 75:639-653.

9. Rawlingson, A. 2003. Nitric oxide, inflammation and acute burn injury. Burns. 29:631-640.

10. Van den Berghe, G., et al. 2001. Intensive insulin therapy in critically ill patients. N. Engl. J. Med. 345:1359-1367.

11. Weekers, F., et al. 2003. Metabolic, endocrine, and immune effects of stress hyperglycemia in a rabbit model of prolonged critical illness. Endocrinology. 144:5329-5338.

12. Hansen, T.K., Thiel, S., Wouters, P.J., Christiansen, J.S., and Van den Berghe, G. 2003. Intensive insulin therapy exerts antiinflammatory effects in critically ill patients and counteracts the adverse effect of low mannose-binding lectin levels. J. Clin. Endocrinol. Metab. 88:1082-1088.

13. Mesotten, D., Swinnen, J.V., Vanderhoydonc, F., Wouters, P.J., and Van den Berghe, G. 2004. Contribution of circulating lipids to the improved outcome of critical illness by glycemic control with intensive insulin therapy. J. Clin. Endocrinol. Metab. 89:219-226.

14. Vanhorebeek, I., et al. 2005. Protection of hepato- cyte mitochondrial ultrastructure and function by strict blood glucose control with insulin in critically ill patients. Lancet. 365:53-59.

15. Knaus, W.A., Draper, E.A., Wagner, D.P., and Zimmerman, J.E. 1985. APACHE II: a severity of disease classification system. Crit. Care Med. 13:818-829.

16. Cowley, H.C., Heney, D., Gearing, A.J., Hemingway, I., and Webster, N.R. 1994. Increased circulating adhesion molecule concentrations in patients with the systemic inflammatory response syndrome: a prospective cohort study. Crit. Care Med. 22:651-657.

17. Sessler, C.N., et al. 1995. Circulating ICAM-1 is increased in septic shock. Am. J. Respir. Crit. Care Med. 151:1420-1427.

18. Cummings, C.J., et al. 1997. Soluble E-selectin levels in sepsis and critical illness. Correlation with infection and hemodynamic dysfunction. Am.J. Respir. Crit. Care Med. 156:431-437.

19. Kayal, S., Jais, J.P., Aguini, N., Chaudiere, J., and Labrousse, J. 1998. Elevated circulating E-selectin, intercellular adhesion molecule 1 , and von Willebrand factor in patients with severe infection. Am. J. Respir. Crit. Care Med. 157:776-784.

20. Whalen, M.J., et al. 2000. Intercellular adhesion molecule- 1 and vascular cell adhesion molecule-1 are increased in the plasma of children with sepsis-induced multiple organ failure. Crit. Care Med. 28:2600-2607.

21. Boldt, J., Wollbruck, M., Kuhn, D., Linke, L.C., and Hempelmann, G. 1995. Do plasma levels of circulating soluble adhesion molecules differ between surviving and nonsurviving critically ill patients? Chest. 107:787-792.

22. Newman, W., et al. 1993. Soluble E-selectin is found in supernatants of activated endothelial cells and is elevated in the serum of patients with septic shock. J. Immunol. 150:644-654.

23. Ma, X.L., Tsao, P.S., and Lefer, A.M. 1991. Antibody to $\mathrm{CD}-18$ exerts endothelial and cardiac protective effects in myocardial ischemia and reperfusion. J. Clin. Invest. 88:1237-1243.

24. Gardinali, M., et al. 2000. Inhibition of CD11CD18 complex prevents acute lung injury and reduces mortality after peritonitis in rabbits. Am. J. Respir. Crit. Care Med. 161:1022-1029.

25. Kakizawa, H., et al. 2004. The relationship between glycemic control and plasma vascular endothelial growth factor and endothelin-1 concentration in diabetic patients. Metabolism. 53:550-555.

26. Chiarelli, F., et al. 2000. Vascular endothelial growth factor (VEGF) in children, adolescents and young adults with type 1 diabetes mellitus: relation to glycaemic control and microvascular complications. Diabet. Med. 17:650-656.

27. Dandona, P., et al. 2003. Insulin suppresses plasma concentration of vascular endothelial growth factor and matrix metalloproteinase-9. Diabetes Care. 26:3310-3314.

28. Ferrara, N., Gerber, H.P., and LeCouter, J. 2003. The biology of VEGF and its receptors. Nat. Med. 9:669-676.

29. Neufeld, G., Cohen, T., Gengrinovitch, S., and Poltorak, Z. 1999. Vascular endothelial growth factor (VEGF) and its receptors. FASEB J. 13:9-22.

30. Tonnesen, M.G., Feng, X., and Clark, R.A. 2000. Angiogenesis in wound healing. J. Investig. Dermatol. Symp. Proc. 5:40-46.

31. Grad, S., et al. 1998. Strongly enhanced serum levels of vascular endothelial growth factor (VEGF) after polytrauma and burn. Clin. Chem. Lab. Med. 36:379-383.

32. Thickett, D.R., Armstrong, L., Christie, S.J., and Millar, A.B. 2001. Vascular endothelial growth factor may contribute to increased vascular permeability in acute respiratory distress syndrome. Am. J. Respir. Crit. Care Med. 164:1601-1605.

33. Infanger, M., et al. 2004. Vascular endothelial growth factor serum level is strongly enhanced after burn injury and correlated with local and general tissue edema. Burns. 30:305-311.

34. Campbell, B., Chuhran, C., and Lefer, A.M. 2000. Vascular endothelial growth factor attenuates trauma-induced injury in rats. Br. J. Pharmacol. 129:71-76.

35. Widenfalk, J., et al. 2003. Vascular endothelial growth factor improves functional outcome and decreases secondary degeneration in experimental spinal cord contusion injury. Neuroscience. 120:951-960.

36. Parrillo, J.E. 1993. Pathogenetic mechanisms of septic shock. N. Engl. J. Med. 328:1471-1477.

37. Dziurdzik, P., Krawczyk, L., Jalowiecki, P., KonderaAnasz, Z., and Menon, L. 2004. Serum interleukin10 in ICU patients with severe acute central nervous system injuries. Inflamm. Res. 53:338-343.

38. Parsons, P.E., et al. 1997. Circulating IL-1ra and 
IL-10 levels are increased but do not predict the development of acute respiratory distress syndrome in at-risk patients. Am. J. Respir. Crit. Care Med. 155:1469-1473.

39. Papathanassoglou, E.D., Movnihan, J.A., Dafni, O., Mantzoros, C.S., and Ackerman, M.H. 2003 Association of proinflammatory molecules with apoptotic markers and survival in critically ill multiple organ dysfunction patients. Biol. Res. Nurs. 5:129-141.

40. Giannoudis, P.V. 2003. Current concepts of the inflammatory response after major trauma: an update [review]. Injury. 34:397-404

41. Dandona, P., Aljada, A., Dhindsa, S., and Garg, R 2003. Insulin as an anti-inflammatory and antiatherosclerotic hormone [review]. Clin. Cornerstone. 4(Suppl.):S13-S20.

42. Aljada, A., and Dandona, P. 2000. Effect of insulin on human aortic endothelial nitric oxide synthase. Metabolism. 49:147-150.

43. Dimmeler, S., et al. 1999. Activation of nitric oxide synthase in endothelial cells by Akt-dependent phosphorylation. Nature. 399:601-605.

44. McCowen, K.C., et al. 2001. Sustained endotoxemia leads to marked down-regulation of early steps in the insulin-signaling cascade. Crit. Care Med. 29:839-846.

45. Cusi, K., et al. 2000. Insulin resistance differentially affects the PI 3-kinase- and MAP kinasemediated signaling in human muscle. J. Clin Invest. 105:311-320.

46. Aljada, A., Ghanim, H., Assian, E., and Dandona, P. 2002. Tumor necrosis factor-alpha inhibits insulin-induced increase in endothelial nitric oxide synthase and reduces insulin receptor content and phosphorylation in human aortic endothelial cells. Metabolism. 51:487-491.

47. Hevel, J.M., White, K.A., and Marletta, M.A. 1991. Purification of the inducible murine macrophage nitric oxide synthase. Identification as a flavoprotein. J. Biol. Chem. 266:22789-22791.

48. Groeneveld, P.H., Kwappenberg, K.M., Langermans,
J.A., Nibbering, P.H., and Curtis, L. 1997. Relation between pro- and anti-inflammatory cytokines and the production of nitric oxide (NO) in severe sepsis. Cytokine. 9:138-142.

49. Thiemermann, C., Ruetten, H., Wu, C.C., and Vane, J.R. 1995. The multiple organ dysfunction syndrome caused by endotoxin in the rat: attenuation of liver dysfunction by inhibitors of nitric oxide synthase. Br. J. Pharmacol. 116:2845-2851.

50. Kilbourn, R.G., et al. 1990. NG-methyl-L-arginine inhibits tumor necrosis factor-induced hypotension: implications for the involvement of nitric oxide. Proc. Natl. Acad. Sci. U. S. A. 87:3629-3632.

51. Kilbourn, R.G., et al. 1990. Reversal of endotoxinmediated shock by NG-methyl-L-arginine, an inhibitor of nitric oxide synthesis. Biochem. Biophys. Res. Commun. 172:1132-1138.

52. Petros, A., et al. 1994. Effects of a nitric oxide synthase inhibitor in humans with septic shock. Cardiovasc. Res. 28:34-39.

53. Lopez, A., et al. 2004. Multiple-center, randomized, placebo-controlled, double-blind study of the nitric oxide synthase inhibitor 546C88: effect on survival in patients with septic shock. Crit. Care Med. 32:21-30.

54. Dandona, P., et al. 2001. Insulin inhibits intranuclear nuclear factor kappaB and stimulates IkappaB in mononuclear cells in obese subjects: evidence for an anti-inflammatory effect? J. Clin. Endocrinol. Metab. 86:3257-3265.

55. Beg, A.A., and Baldwin, A.S., Jr. 1993. The I kappa $B$ proteins: multifunctional regulators of Rel/NFkappa B transcription factors [review]. Genes Dev. 7:2064-2070

56. Mesotten, D., et al. 2002. Regulation of insulinlike growth factor binding protein-1 during protracted critical illness. J. Clin. Endocrinol. Metab. 87:5516-5523

57. Aljada, A., et al. 2004. Increase in intranuclear nuclear factor kappaB and decrease in inhibitor kappaB in mononuclear cells after a mixed meal evidence for a proinflammatory effect. Am. J. Clin.
Nutr. 79:682-690

58. Dhindsa, S., et al. 2004. Differential effects of glucose and alcohol on reactive oxygen species generation and intranuclear nuclear factor-kappaB in mononuclear cells. Metabolism. 53:330-334.

59. Van den Berghe, G. 2004. How does blood glucose control with insulin save lives in intensive care? [review]. J. Clin. Invest. 114:1187-1195. doi:10.1172/ JCI200423506.

60. Giugliano, D., Ceriello, A., and Paolisso, G. 1996. Oxidative stress and diabetic vascular complications. Diabetes Care. 19:257-267.

61. West, I.C. 2000. Radicals and oxidative stress in diabetes. Diabet. Med. 17:171-180

62. Brownlee, M. 2001. Biochemistry and molecular cell biology of diabetic complications. Nature. 414:813-820.

63. Hunt, J.V., Dean, R.T., and Wolff, S.P. 1988. Hydroxyl radical production and autoxidative glycosylation. Glucose autoxidation as the cause of protein damage in the experimental glycation model of diabetes mellitus and ageing. Biochem. J. 256:205-212.

64. Bonnefont-Rousselot, D. 2002. Glucose and reactive oxygen species. Curr. Opin. Clin. Nutr. Metab. Care. 5:561-568.

65. Weekers, F., et al. 2002. A novel in vivo rabbit model of hypercatabolic critical illness reveals a biphasic neuroendocrine stress response. Endocrinology. 143:764-774

66. Giovannoni, G., Land, J.M., Keir, G., Thompson, E.J., and Heales, S.J. 1997. Adaptation of the nitrate reductase and Griess reaction methods for the measurement of serum nitrate plus nitrite levels. Ann. Clin. Biochem. 34:193-198.

67. Brealey, D., et al. 2002. Association between mitochondrial dysfunction and severity and outcome of septic shock. Lancet. 360:219-223.

68. Miranda, D.R., de Rijk, A., and Schaufeli, W. 1996. Simplified therapeutic intervention scoring system: the TISS-28 items - results from a multicenter study. Crit. Care Med. 24:64-73. 